\title{
Arktiline kunst
}

\author{
Jean-Loup Rousselot
}

\begin{abstract}
Teesid
Kanada eskimode ehk inuitide elujärg sõltus pikka aega jahindussaaduste, täpsemalt karusnaha hindadest. Nende liikuv elulaad ei võimaldanud soetada majapidamisse liigseid esemeid, seetõttu piirdus sealsete inimeste algne kunstiline eneseväljendus tarbeesemete kaunistamisega, sh ka nn jutustamist hõlbustavate pildiridadega. Pärast Teist maailmasõda algatas Kanada valitsus Hudsoni lahe äärsete elanike toetamise pilootprojekti, tehes kunstnik James A. Houstonile (sünd 1921) ülesandeks luua pisiplastikakavandeid, mille alusel kohalikud võiksid toota turistidele müümiseks steatiitskulptuure. Alles 60 aasta eest alguse saanud rahvakunstiliik on nüüdseks andnud hulga huvitava kunstnikukäekirjaga arktilise kunsti esindajaid, nagu Keewatinist pärit minimalisti Lucy Tasseorit, Joanassie'd (Joanassie Manning) Cape Dorsetist ja Peter Sevogat Baker Lake'ist. Kunstniku positsioon tema kodukogukonnas on kõrge.
\end{abstract}

Märksõnad: arktiline kunst, inuitid, Kanada, piktograafilised pildiread, pisiplastika, steatiitskulptuur

Arktilised jahimehed - eskimod ${ }^{1}$ - elatusid veel viiekümne aasta eest eranditult jahindusest ega olnud paikseks jäänud nagu tänapäeval. Et säilitada vajalikku mobiilsust, pidid nende tarberiistad olema kerged ja kaasaskantavad. Kogu majapidamiskraami veeti talvel kelkude ja suvel nahkpaatidega (avatud kajakk-ja suletud umiaksüstadega). Et aastaaegade vaheldumisest tingitud dihhotoomiad talv - suvi, pimedus - valgus, külmunud - sulanud, meri - maa kujundasid ja mõjustasid nii inimeste kui ka loomade käitumist, erinesid talvised ellujäämistehnikad suvistest sedavõrd, et kummagi aastaaja tarbeks tuli valmistada spetsiifilised relvad, tööriistad, hooned, sõidukid, riietus jne. Üleminekuajad - kevad ja sügis - olid nii lühikesed, et neid ei tajutud aastaaegadena. Et oma mobiilsust mitte pärssida, pidi jahimees üleliigse varustuse hoiule panema: ta asetas selle mõnele kuivemale kohale ja kattis hoolikalt kividega.

Selle nomaadsete jahimeeste eluviisi lühikese kirjeldusega tahan viidata asjaolule, et majapidamistes ei tohtinud olla mingeid üleliigseid esemeid. Iga objekti vajalikkust kaaluti hoolikalt, arvestades koerarakendite ja nahkpaatide kandevõimet. Seetõttu ei leidu traditsioonilistes arktilistes kultuurides kunstiteoseid, mis olek- 


\section{Jean-Loup Rousselot}

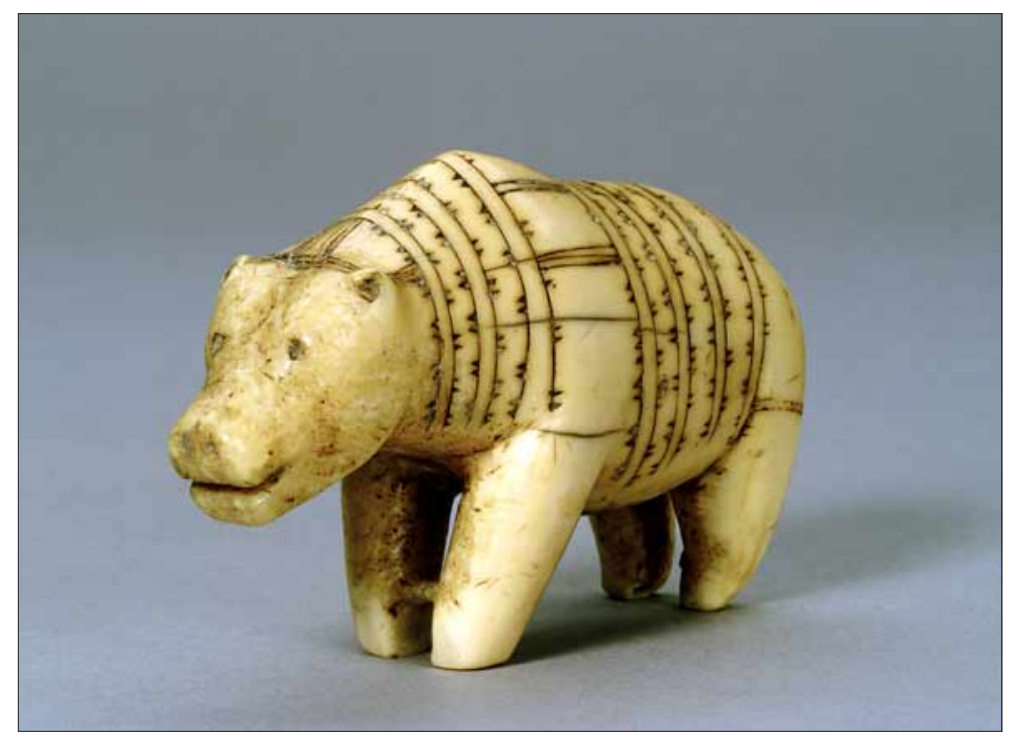

Foto 1. Neljakäpakil jääkaru avatud suu ja lineaarsete kaunistustega. Morsaluust amulett. Ida-Siber (u 1850). 6,5x10x3,4 cm. Karl von Ditmari kogu, Eesti Ajaloomuuseum, Tallinn (K-1648).

sid valmistatud puhtalt kunstikaalutuslikel eesmärkidel, vaid igal objektil on oma praktiline funktsioon. Relvad, paadid ja rõivad mõjuvad kunstipäraselt ja elegantselt. Need on aga omadused, mis jäävad küll funktsionaalsuse parameetritest väljapoole, kuid neil on usundilises mõttes siiski kindel otstarve: loom tuli peibutuslaulu kuuldes talle vastu ja laskis end kauniste jahiriistadega kütil tabada, teades, et nende omanik peab kindlasti kinni kõikidest ettenähtud tabudest, et tagada looma taassünd; loom sai ka aru, et inimesed kannatavad nälga ja vajavad tema liha.

Esteetilisi taotlusi võib märgata ka amulettide juures. Need kujutavad kaitsevaime ja abilisi, kes aitavad näiteks jahil. Amuletid olid enamasti üsna väikesed $-4-6 \mathrm{~cm}$ pikkused puidust, harvadel juhtudel ka morsakihvadest, kuid mitte kunagi kivist skulptuurid. Arktilises kontekstis oli ajupuu amulettide tegemiseks haruldasem ja väärtuslikum kui morsakihvad. Figuurid olid väikesed, sest pidid mahtuma seljakotti või vööl kantavasse taskusse. Neid tuli pigem pihku võtta ja tunnetada ning nendega nõu pidada, neid ei saanud püsti seisma panna (pealegi ei olnud jahimeeste kogukonnas mööblit). 
Niisugused figuurid, mida võib kohata väljakaevamistel ja vanades etnograafilistes kogumikes, kujutavad sageli loomi, nt jääkarusid (foto 1) või linde, aga ka inimesi. Enamasti torsona kujutatud inimfiguuridel on vahel algeliselt töödeldud käed. Need skulptuurid on tänapäeval kunstikogujate seas ülihinnatud.

\section{Graafiline kunst}

Järgnevalt kirjeldatavat kunstilise väljenduse vormi võib leida kogu Arktikas, eelkõige aga siiski Alaskal - nimelt kaljudel, loomaluudel ja puidul kujutatud loomi ja sündmusi (foto 2). Tegemist on piktograafilise jäädvustamise vormiga, mille abil püüti meeles pidada mingeid olulisi elamusi. Kui taheti sündmusi taasesitada, ka-

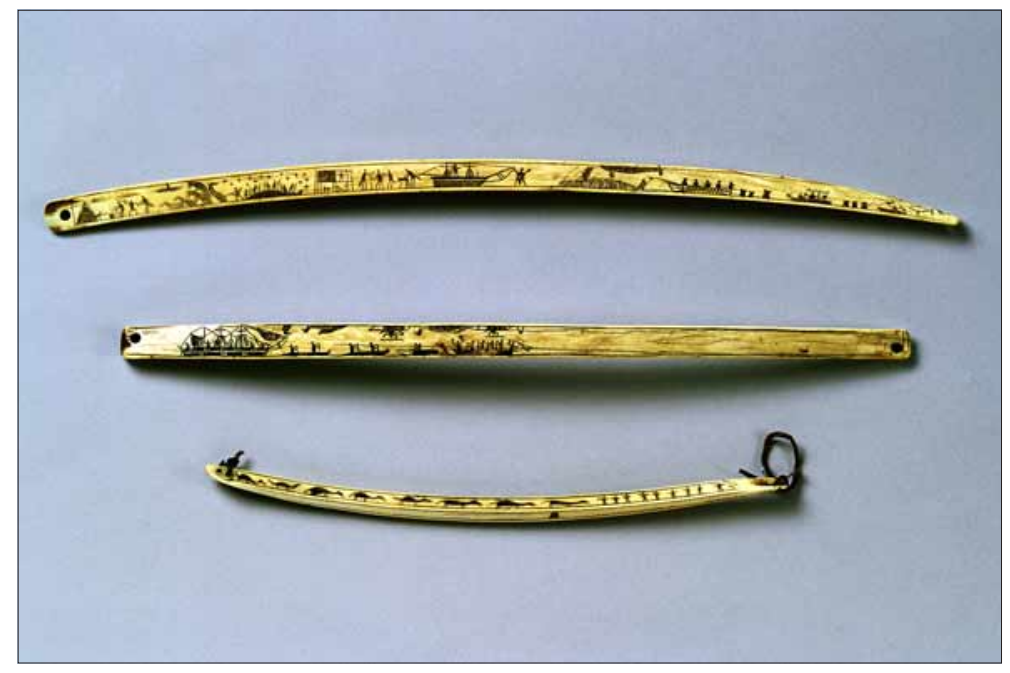

Foto 2. Vibupuuri vibul paiknevad piktogrammid. Niisugused "märkmeraamatud” jutustavad olulistest sündmustest kunstniku elus. Need olid enne eurooplaste saabumist laialt kasutusel, nagu võib järeldada esimestelt Alaska-ekspeditsioonidelt kogutud objektide põhjal. Kui kontaktid Euroopaga sagenesid (19. sajandi II pool), sai nendest ihaldatud suveniir, mille stiil kohandati klientide soovidele (Ray 1977:214-240).

Morsaluust kepp 1x49,5x1,7 cm. Inupiat, Sewardi poolsaare lõunarannik, enne 1836. aastat. Ferdinand von Wrangelli kogu, Eesti Ajaloomuuseum, Tallinn (K-2295/1). 


\section{Jean-Loup Rousselot}

sutati seda spikrina ja aeti rääkimise ajal piltidelt järge. Niisuguseid dokumente võib näha paljudes muuseumides, sest 19. sajandi rännumehed võtsid neid meelsasti suveniirina kaasa. Kui üksikutest piktogrammidest on enamasti veel võimalik aru saada, siis nende tummade kujutiste seosed jäävad tänapäeval ilma kommentaatori kohalolekuta peaaegu mõistetamatuks. Ilma teate anda kavatsusi tundmata on interpreteerimine õigupoolest võimatu.

Inupiaq' rahvakild, mis asustab Sewardi poolsaart (Alaska), elas 19. sajandil peamiselt hülge- ja morsajahist, sügiseti aga keskenduti põhjapõdrajahile. Kohati õnnestus tabada ka suuri (grööni) vaalu, kui vaalade rändeteed möödusid ranniku lähedalt. Jahimeestel oli kombeks graveerida isiklikele tööriistadele stseene õnnestunud jahiretkedest. Sageli võis selliseid kujutisi leida vibupuuri vibult. Edu jahil lisas jahimehele ühiskondlikku prestiiži, sest korrapärane piisava toiduga varustamine nõudis jahindusest elatuvas kogukonnas palju pingutust ja tööd. Sellega said hakkama ainult kogenud jahimehed, kes tundsid hästi loomade käitumist ja püügitehnikaid, aga valdasid ka salajasi mõjuvõimsaid jahilaule ja omasid talismane.

\section{Tänapäeva Kanada pärismaine kunst}

Tänapäevases kunstis võib kogeda mitmekesisust ja dünaamikat, mis viitavad vaieldamatult asjaolule, et arktilised kultuurid osalevad intensiivselt ühiskondlikes muutustes. Tuntuim ja samas ka kõige paremini müüv pärismaine kunst pärineb Kanadast. Et see mõjub põlisemalt ja on seetõttu ka muudest paremini turustatav, vaadeldakse seda järgmises lõigus lähemalt.

Euroopa karusnahakaupmeeste saabumine 19. sajandil tõi seni võrdlemisi isoleerituks jäänud arktilistesse kultuuridesse põhjapanevaid muudatusi. Sellest ajast peale said jahimehed, kes olid varunud piisavalt karusnahku, elatada oma perekondi nahkade vastu vahetatud toiduainetest, mis pärinesid karusnahakaupmeeste tagavaradest. Juhtudel, kui nahahinnad langesid või ei suudetud küttida piisavalt loomi, olid raskekujulised tagajärjed, sest siis ei saanud trapperi perekond endale lubada lõuna poolt imporditud asju. Jahimehed olid jätnud suuresti kõrvale lihaloomade jahtimise, et keskenduda rohkem karusloomade küttimisele, seega polnud perekondadel ja koertel enam piisavalt liha. Seetõttu tabasid jahimehi-trappereid, kes võimalikult suurte jahimaade haldamise huvides 
elasid väikeste isoleeritud rühmadena, 20. sajandi 30. ja 40. aastatel näljahädad.

Pärast Teist maailmasõda algatas Kanada valitsus pilootprojekti, pidi kindlustama jahimeestele kindla sissetuleku, vähendades selle sõltuvust karusnahahindade kõikumisest. Tuginedes paljude rändurite teateile eskimode headest nikerdamisoskustest, anti kunstnik James A. Houstonile (sünd 1921) ülesanne õhutadaHudsoni lahe läheduses elavaid rühmi eriti tõsiste näljahädade käes kannatavaid rühmi valmistama loomaskulptuure kunstiäri jaoks. Skulptuurid pidid olema steatiidist - pehmest kivimist, mille leiukohti on kõnealuses piirkonnas.

Traditsioonilises kultuuris nikerdati sellest kivimist küll traanilampe (vaala- või hülgerasvalambid) ja keedupotte, kuid mitte skulptuure. J. A. Houston pakkus potentsiaalsetele kiviraiduritele välja mõned teemad ja joonistas isegi visandid kujutistest, mida ta nägi vaimusilmas ja mida vajas maa lõunaosa kunstiäri: vaprad jahimehed, võitmatud jääkarud, harmoonilised perekonnastseenid.

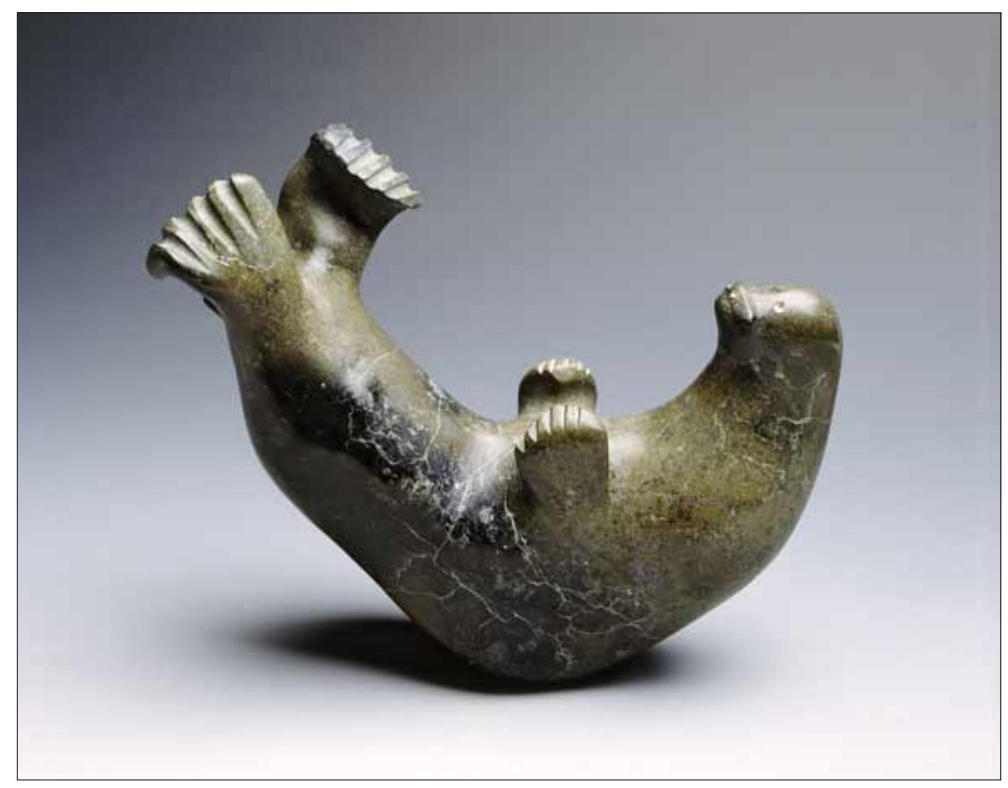

Foto 3. Hüljes kevadisel jääl päikese käes peesitamas. $25 \times 30 \times 10 \mathrm{~cm}$. Steatiitskulptuur. Kunstnik Pauta Saila (Cape Dorset, Kanada, 1977). Lorne Balshine kogu, Müncheni Riiklik Etnoloogiamuuseum (88310372). 


\section{Jean-Loup Rousselot}

Skulptuur pidi olema realistlik, detailid aga abstraheeritud; massiivsed ümarad vormid pidid viitama arktiliste elanike loomuomasele kartmatusele, sile pealispind oli mõeldud tekitama soovi puutekontakti järele ja ühtlasi sümboliseerima nende rahvaste heasüdamlikkust. Seda projekti saatis peagi suur edu. Eskimod, kes muuseas nimetavad ennast selles Kanada piirkonnas inuitideks, järgisid alguses suuniseid, arendasid aga peagi välja oma motiivid ja teemad. Samal ajal hoolitsesid ametkonnad selle eest, et töödel oleks turgu. Aja möödudes vabanesid mõned kunstnikud etteantud raamidest, arendasid täiesti uusi suundi ja kuuluvad tänaseks 20. sajandi olulisimate loojate ridadesse. Ma mõtlen siinkohal eriti Keewatinist pärit minimalisti Lucy Tasseori, Joanassie'd (Joanassie Manning) Cape Dorsetist ja Peter Sevogat Baker Lake'ist.

Nüüdseks, 60 aastat pärast inuiti kunsti tekkimist on selles leidnud aset mõnedki arengud. Levinuimaks motiiviks on nüüdki loomad, kõndivad või end tagakäppadele püsti ajavad jääkarud, jäätükil kevadpäikese käes peesitavad hülged (vt foto 3). Leidub ka loomavõitluse motiive, näiteks jääkaru ja morsk teineteist ründamas. Teisalt leidub pildikesi argipäevast: sageli kujutatakse ema, kes kannab last oma kuue kapuutsis, samuti jahistseene, näiteks ebavõrdset võitlust vaid noaga relvastatud jahimehe ja jääkaru vahel.

Lõpututes variatsioonide käsitletakse ka mõningaid mütoloogiast ja jutupärimusest võetud teemasid. Mereloomade jumalanna Sedna, keda kujutatakse naise ülakeha ja kala alakehaga olendina, võib nagu loomadki inimeseks muunduda. Eespool märgitud duaalsust kohtab ka usundilistes kujutelmades. Loomadel on hing, mis on oma loomuselt inimlik, inimese hing on aga loom.

Nüüdisaegsed kunstnikud kasutavad kõiki Arktikas esinevaid ja varem igapäevases tarbes kasutusel olnud klassikalisi materjale - steatiiti, sarvi, vaalaluud, morsakihvu, nahka.

Värvilised joonistused ja riisipaberil kivitrükk pakuvad kunstnikele samuti hulgaliselt eneseväljendusvõimalusi. Graafikateoste puhul võib veel enam kui skulptuuride puhul täheldada vaba ümberkäimist traditsiooniga, kuigi vormilt järgivad need sageli graveerimistehnikas joonistusi. Joonistustel käsitletakse ka aktuaalseid teemasid, nagu keskkond ja poliitika (vt nt foto 4).

Lõpuks tahaksin juhtida tähelepanu sellele, kui olulised on tänapäeval kunstnikud nende kodukogukondadele. Edu ja tunnustus, 


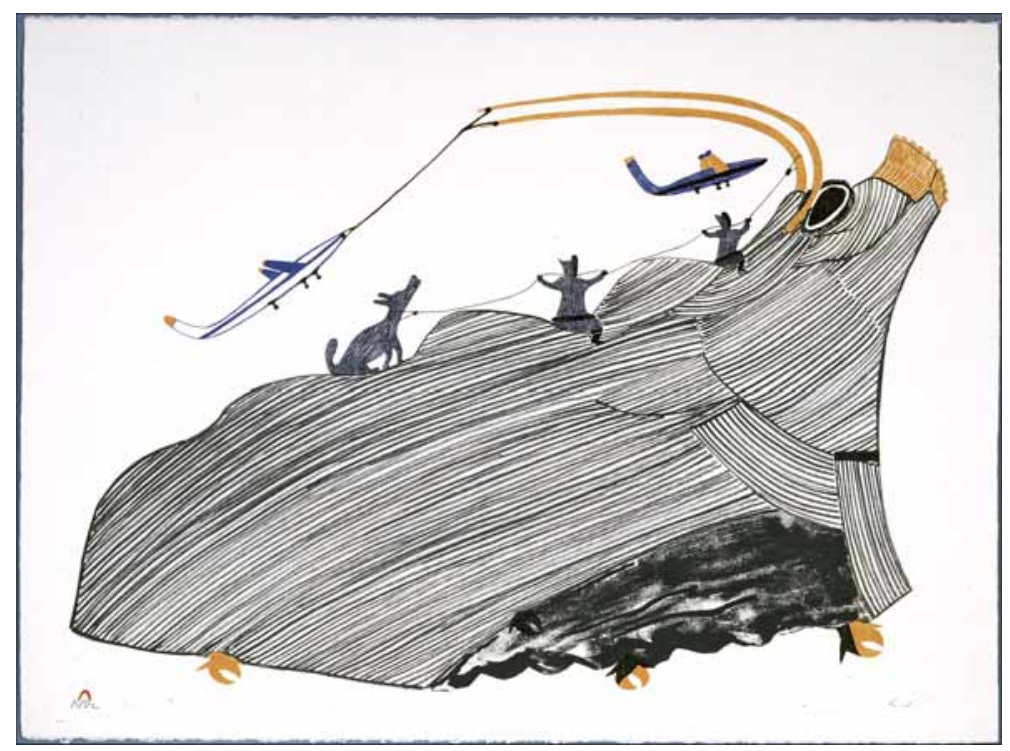

Foto 4. Muutuste tuuled. 57x76,5 cm. Pudlo Pudlati (1916-1992) värviline litograafia. Cape Dorset, Kanada, 1985. Erakogu, München (881126-01).

Muskusveis, kelle seljas ronivad kaks meest ja koer. Mööda lendab lennuk, teine õhusõiduk on kinnitatud köiega looma sarvede külge. Hiigelelukas võitleb kõigest jõust inimese, koera ja lennuki vastu, kes tahavad teda kaasaegseimate vahendite abil kinni püüda. Litograafia on loodud ühe aastatest 1983-1984 pärineva joonistuse järgi.

mis kunstnikke saadavad, tugevdavad kogu rühma etnilist iseteadvust ja kultuurilist identiteeti ning aitavad omakorda kaasa traditsioonide säilimisele.

Kuigi paljudel kunstnikel on juba aastaid ligipääs moodsale tehnikale, luuakse oma veebilehti ja võetakse interneti teel vastu tellimusi, on pakane, pimedus, tundra ja jahiloomad kohe ateljee ukse tagant algav reaalsus. Kui kunstnik lahkub oma mugavast ja nüüdisaegsest kodust, on ta looduses, mis on talle ühenduslüliks esivanemate ja nende maailmaga, viimases aga liigub ta ringi täie enesestmõistetavusega, mis täidab väljaspool seisja aukartuse ja imetlusega.

Tõlkinud Reet Hiiemäe 
Jean-Loup Rousselot

\section{Kommentaar}

${ }^{1}$ Tänapäeval eelistatakse kasutada rahvakildude omanimetusi. Need on Gröönimaal kalaallit, Kanadas inuit, Alaskal inupiak, jupik ja alutiik ning Ida-Siberis juit.

\section{Kirjandus}

Kaalund, Bodil 1983. The Art of Greenland: Sculpture, crafts, painting. Berkeley et al.: University of California Press.

Malaurie, Jean (toim) 2001. L'art du Grand Nord. L'art et les grandes civilisations 31. Paris: Citadelles \& Mazenod.

Ray, Dorothy Jean 1977. Eskimo Art: Tradition and innovation in north Alaska. Index of art in the Pacific Northwest 11. Seattle: Henry Art Gallery \& University of Washington Press.

Ray, Dorothy Jean 1981. Aleut and Eskimo Art: Tradition and Innovation in South Alaska. Seattle: University of Washington Press.

Rousselot, Jean-Loup 1994. Kanuitpit?: Kunst und Kulturen der Eskimo. München: Staatliches Museum für Völkerkunde.

Rousselot, Jean-Loup \& Abel, Bernard \& Pierre, José 1992. Eskimomasken aus Alaska. Art \& Ethnologie. Saint-Vit: Éditions Amez.

Schulze-Thulin, Axel (koost) 1983. Inuitkunst - Kunst der Eskimo: Stein, Elfenbein, Knochen, Geweih. Stuttgart: Linden-Museum.

Traeger, Verena 1991. Eskimokunst. Feest, Christian F. (toim). Eskimo: Schwerpunkt Grönland:Am Nordrand der Welt. Wien: Museum für Völkerkunde, lk 98-108. 